\title{
Numerical Simulation of Laser Welding of Thin-wall Aluminum Alloy
}

\author{
Wei Duan ${ }^{1, \text { a) }}$, Ting Jiang ${ }^{2}$ and Lihong Zhou ${ }^{1}$ \\ ${ }^{1}$ City College, Wuhan University of Science and Technology, Wuhan 4301083, China. \\ ${ }^{2}$ General Hospital of the Yangtze River Shipping, Wuhan 430010, China \\ a)davidjiangyi@foxmail.com
}

\begin{abstract}
The simulation of thin-walled aluminum alloy laser welding was carried out in this paper. It is analyzed for the temperature field of thin-walled aluminum alloy laser welding in various laser power and scan speed. The simulation results show that with the increase of laser power, the area of heat affected zone increases, and with the increase of welding speed, the cross sectional area of molten pool decreases.
\end{abstract}

Keywords: Numerical Simulation, Laser Welding, Thin-Walled Aluminum Alloy

\section{INTRODUCTION}

Laser welding forming is a welding process using high intensity laser irradiation material to link the material ${ }^{[1]}$. Because of laser welding process compared with the traditional welding process, has a high energy density, forming speed and the advantages of small welding deformation, it has a broad application prospect in many areas. In the process of laser welding process, temperature field distribution is an important factor affecting the quality of welding parts, analysis of temperature field in the process of forming parts for reasonable design of laser technology, improve the quality of the parts is of great significance ${ }^{[2-3]}$. Because the experiment itself is mostly long and expensive, the study of laser welding forming process by means of experimental measurement will result in serious waste of time cost and material cost. In addition, due to the limitations of the experimental measurement, such as physical field distribution and physical evolution process cannot be accurately described. Therefore, it is very urgent and necessary to carry out research on laser welding process using computer numerical simulation technology ${ }^{[4]}$.

The process parameters discussed in this paper mainly include laser speed and laser power. The influence of process parameters on weld pool was studied by control variable method, which provided the basis for setting reasonable process parameters.

\section{MODELS}

\section{Physical model}

In the process of laser welding, heat transfer involves three forms: heat conduction, convection and radiation. Among them, the laser energy is input to the surface of the material in the way of heat flux density, and it is transmitted to the matrix in the form of heat conduction, or the solder is formed first. The heat transfer control equation satisfies the Fourier law ${ }^{[5]}$, and the expression is as formula (1):

$$
\rho \mathrm{C}_{p}\left(\frac{\partial T}{\partial t}\right)=\nabla \cdot(\nabla \lambda T)+Q
$$


Where, ${ }^{\mathrm{C}_{p}}$ is specific heat of material, $\rho$ is density of material, $\lambda$ is coefficient of thermal conductivity, ${ }^{T}$ is temperature field distribution function, $Q$ is heat resource, and ${ }^{t}$ is time.

Before the start of laser welding, it is assumed that the solder and the substrate have a consistent initial temperature.

$$
\left.T_{(x, y, z, t)}\right|_{t=0}=T_{0}
$$

In the process of laser welding, the upper surface of the cladding layer and the heat convection in the form of heat convection exist on all sides. Because the laser processing time is extremely short, the influence of thermal radiation can be neglected in the calculation, only the convection heat transfer between the cladding layer and the surrounding air is considered. The boundary conditions can be described as equation (3):

$$
-k\left(\frac{\partial T}{\partial \vec{n}}\right)=h\left(T-T_{\infty}\right)
$$

In equation (2) and (3), the thermal conductivity is expressed as $k$, the convective heat transfer coefficient of air is expressed as $h, T_{0}$ is the initial temperature, $T_{\infty}$ is the ambient temperature and $T$ is the temperature distribution function.

The effective power of the heat source is shown below equation (4) - (7):

$$
\begin{array}{r}
P=\eta U I=P_{s}+P_{v} \\
P_{v}=\lambda P \\
P_{s}=(1-\lambda) P \\
r=(x-v t)^{2}+y^{2}
\end{array}
$$

The equation of surface heat source is as equation (8):

$$
P_{s}=\int_{0}^{2 \pi+\infty} \int_{-\infty}^{+\infty} q_{m} \exp \left(-\frac{a r^{2}}{\sigma^{2}}\right) r d r d \theta
$$

The equation of body heat source is as equation (9):

$$
P_{v}=\int_{0}^{2 \pi} \int_{-\infty}^{+\infty} \int_{0}^{b} Q_{m} \exp \left(-\frac{b r^{2}}{r^{2}}\right)\left(\frac{m z+r_{0}}{r_{0}}\right) r d y d r d \theta
$$

Where, $P$ is the total effective power of a reservoir, $P_{s}$ is the surface source power, $P_{v}$ is the body heat source power, $\eta$ is the welding thermal efficiency, $\lambda$ is the body heat source distribution coefficient, $U$ is the acceleration voltage, $I$ is the laser current, $v$ is welding speed, $q_{m}$ is the heat flux density of a surface reservoir, $\sigma$ is heat flow distribution parameters, $a$ is the heat source set parameter, $Q_{m}$ is the heat flux density of body heat source, $m<0$ is the attenuation coefficient of endogenous heat, $b$ is the endogenous heat concentration coefficient, and $r_{0}$ is effective radius of cylinder heat source.

\section{The establishment of laser welding geometry model}

In this paper, UG is used to establish the laser welding entity model, as shown in figure 1 . The size of the study base plate is $200 \times 100 \times 1.4 \mathrm{~mm}$, and the vertical plate size is $200 \times 22 \times 1.4 \mathrm{~mm}$. Grid division is an important element in finite element thermal analysis, and the quality of grid division directly affects the accuracy and efficiency of numerical simulation results. Generally speaking, the smaller the grid size is, the higher the calculation precision is, but at the same time, the grid oversize will increase the number of grids and increase the computation, 
thus reducing the computational efficiency. Therefore, in order to a good balance in efficiency and precision of the results, in the process of calculation to non-uniform grid division, and in the process of forming, this paper takes the form of adaptive grid.

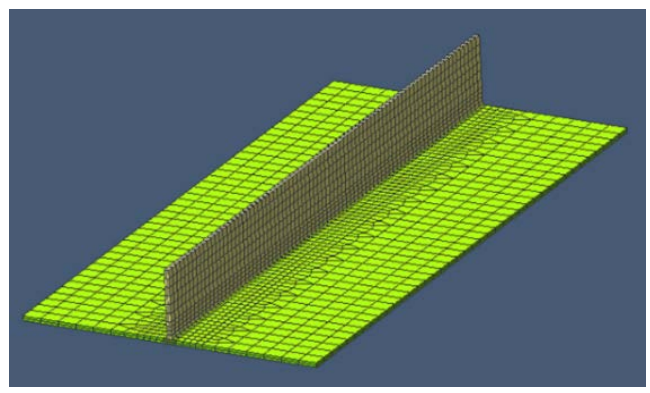

FIGURE 1. Grids division of laser welding model.

\section{SIMULATION RESULTS AND ANALYSIS}

\section{The influence of laser power on temperature field}

As a result of the laser welding, laser power has great influence on welding temperature, the first in other process parameters will not affect the test results, change the laser power to carry out the numerical simulation of temperature field and the result analysis. In the process of welding laser power affect the welding temperature, the size of the first change of laser power, keep the welding speed constant laser power is $1800 \mathrm{w}$ and the original design of the temperature field of the laser power $1080 \mathrm{w}$. Three time points were taken: $4 \mathrm{~s}, 8 \mathrm{~s}, 12 \mathrm{~s}$.
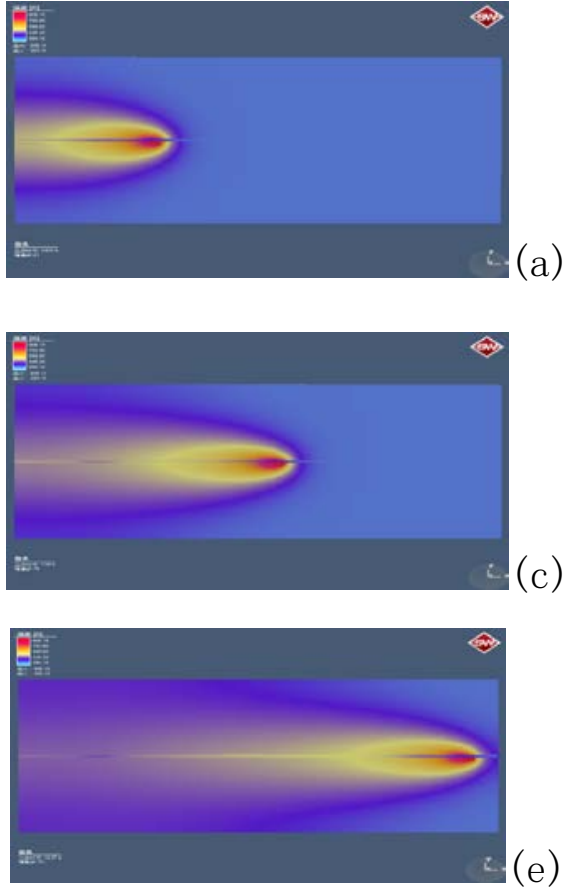
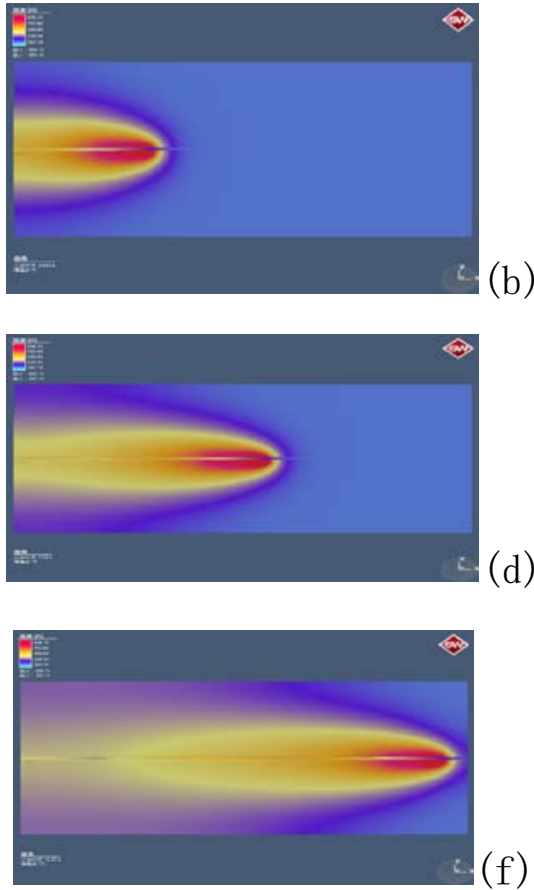

FIGURE 2. Temperature filed during laser welding: (a) $1080 \mathrm{~W}, 4 \mathrm{~s}$; (b) $1800 \mathrm{~W}, 4 \mathrm{~s}$; (c) $1080 \mathrm{~W}, 8 \mathrm{~s}$; (d) $1800 \mathrm{~W}, 8 \mathrm{~s}$; (e) $1080 \mathrm{~W}, 12 \mathrm{~s}$; (f) $1080 \mathrm{~W}, 12 \mathrm{~s}$. 
As shown in figure 2, through the different time, the power of $1800 \mathrm{w}$ control the temperature field cloud picture and the original power of $1080 \mathrm{w}$, comparing the temperature field cloud picture can draw the following conclusions: (1) the greater the power, the highest temperature of molten pool, the greater the increase of heat affected zone, in the mid-late welding, molten pool longitudinal size increased significantly;(2) the greater the power, near the weld temperature gradient increased obviously, this brought greater stress and strain to weldment, also increased the possibility of welding cracking and the trend of the welding crack.(3) the laser power increases, also brought different preheating system, while at the same time of $4 \mathrm{~s}$, when the power is $1800 \mathrm{w}$, weldment geometry center of the highest temperature is $600{ }^{\circ} \mathrm{C}$, the highest temperature is higher than when the power is $1080 \mathrm{w}, 478{ }^{\circ} \mathrm{C}$, show before the arrival of the heat source, phase change have taken place in material.

\section{The effect of laser scanning speed on molten pool}

In addition to laser power, laser scanning speed is also an important parameter in welding forming process, which greatly influences the quality of forming. FIG. 3 is a comparison and analysis of the molten pool section of the original process with the welding speed of $30 \mathrm{~mm} / \mathrm{s}$ and the welding speed of $15 \mathrm{~mm} / \mathrm{s}$ to keep the laser power 1080W unchanged.
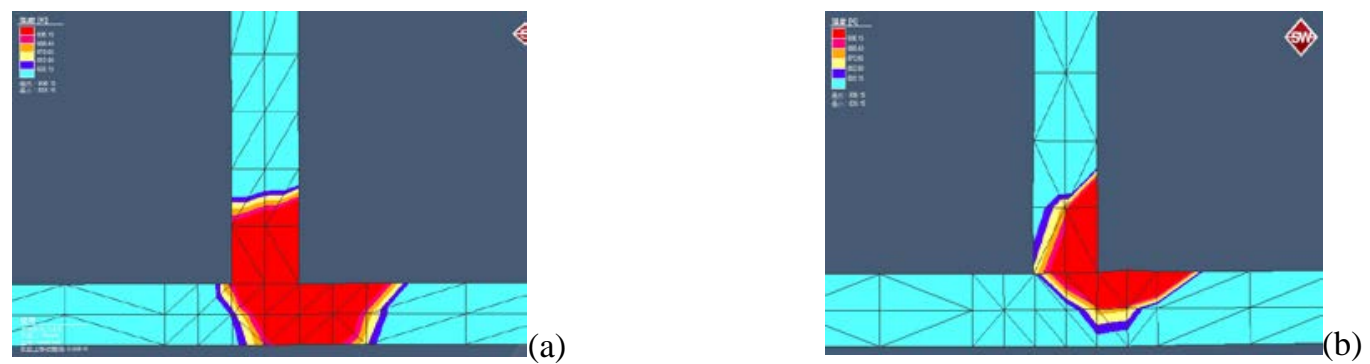

FIGURE 3. Cross section of molten pool: (a) $1080 \mathrm{~W}, 15 \mathrm{~mm} / \mathrm{s}$; (b) $1080 \mathrm{~W}, 30 \mathrm{~mm} / \mathrm{s}$.

As can be seen from figure 3, the welding speed increases and the weld pool section decreases. The faster the welding speed is, the lighter the depth of the weld pool will be, and the speed of the weld will affect the quality of the welding parts, and the welding may not be transmitted or not completely welded. If too slow, the weld penetration will be too deep, and the welding quality will be affected.

\section{CONCLUSION}

In this paper, the numerical simulation of thin-wall aluminum alloy laser welding is carried out, and the temperature field of different laser power and scanning speed are studied, and the following conclusions are drawn: (1) With the increase of laser power, the area of heat affected zone increases; (2) With the increase of welding speed, the cross sectional area of molten pool decreases; (3) Numerical simulation technology is an effective method for the fabrication of thin wall aluminum alloy laser welding .

\section{REFERENCES}

1. Swift-Hook D T, Gick A E F. Penetration welding with lasers[J]. Welding journal, 1973, 52(11): 492s-499s.

2. Reinhart G, Lenz B, Rick F. Finite element simulation for the planning of laser welding applications[J]. Laser Institute of America, Laser Materials Processing, 2000, 87.

3. Meco S, Cozzolino L, Ganguly S, et al. Laser welding of steel to aluminium: Thermal modelling and joint strength analysis[J]. Journal of Materials Processing Technology, 2017.

4. Tian Y, Robson J D, Riekehr S, et al. Process Optimization of Dual-Laser Beam Welding of Advanced Al-Li Alloys Through Hot Cracking Susceptibility Modeling[J]. Metallurgical and Materials Transactions A, 2016, 47(7): 3533-3544.

5. Childs T H C, Berzins M, Ryder G R, et al. Selective laser sintering of an amorphous polymer-simulations and experiments[J]. Proceedings of the Institution of Mechanical Engineers, Part B: Journal of Engineering Manufacture, 1999, 213(4): 333-349. 